\title{
Mechanisms of Endotoxin Tolerance
}

\author{
THE ROLE OF THE SPLEEN
}

\author{
Sheldon E. Greisman, Edward J. Young, Joseph B. Workman, \\ Robert M. Ollodart, and Richard B. Hornick
}

From the Departments of Medicine and Physiology, University of Maryland School of Medicine, Baltimore, Maryland 21201

A в S T R A C T Splenectomy markedly impaired the production of circulating anti-endotoxin antibodies during the initial 10 days after i.v. administration of a Boivin preparation of Escherichia coli endotoxin (ET) in both rabbit and man. Increases in antibodies with secondary (flocculating and bactericidal) activities were virtually abolished, whereas increases in antibodies with primary (binding) activity were significantly reduced. On the basis of these findings, splenectomized rabbit and man were employed to test the hypothesis that the early phase $(<72 \mathrm{~h})$ of pyrogenic tolerance to endotoxin is independent of anti-endotoxin antibody but that such antibody contributes significantly to the later phase $(\geq 72 \mathrm{~h}$ ) of tolerance.

In the splenectomized rabbit, the initial pyrogenic responses to $\mathrm{ET}$ and the subsequent tolerant responses at 24 and $48 \mathrm{~h}$ were comparable to sham-operated controls. Thereafter, splenectomized rabbits exhibited impaired ability to acquire further pyrogenic tolerance. Such impairment was evidenced by significantly retarded rates of tolerance commencing $72 \mathrm{~h}$ after daily i.v. injections of ET and by significantly reduced tolerance 5 days after a single i.v. injection of ET. Similarly, healthy splenectomized human volunteers exhibited pyrogenic and subjective toxic responses to an initial i.v. injection of ET comparable to volunteers with intact spleens. Upon retesting 5 days later, however, the splenectomized volunteers exhibited significantly reduced levels of tolerance. When additional ET was subsequently administered, tolerance increased progressively in all volunteers, but its rate of maturation was significantly retarded in the splenectomized subjects. To reproduce equivalent impairment of the late phase of tolerance in volunteers with intact spleens, the immunizing doses of ET had to be decreased to levels extrapo-

Received for publication 18 March 1975 and in reised form 31 July 1975. lated to fall between $1 / 10$ and $1 / 100$ of those used in the splenectomized subjects. The impairment of latephase pyrogenic tolerance after splenectomy appeared to be the result of the concomitant suppression of antiendotoxin antibody production rather than the loss of splenic reticuloendothelium required to clear and inactivate the ET. This was evidenced by: $(a)$ the significant retardation in appearance of humoral factors in the splenectomized rabbits capable of transferring high levels of specific tolerance; $(b)$ the inability to impair the late phase of tolerance in human volunteers with intact spleens until the immunizing doses of endotoxin were reduced to levels that virtually eliminated circulating anti-endotoxin antibody production; $(c)$ the unimpaired development of tolerance in partially hepatectomized rabbits lacking more functional reticuloendothelium than splenectomized animals, but capable of normal anti-endotoxin antibody synthesis.

It is concluded that in rabbit and man the spleen plays no important role in the initial pyrogenic response to i.v. ET, or in the early phase of pyrogenic tolerance. The spleen, however, by virtue of its anti-endotoxin antibody-producing capabilities, contributes significantly to the late phase of tolerance after a single i.v. injection of ET and accelerates significantly its rate of acquisition after repetitive i.v. injections of the toxin.

\section{INTRODUCTION}

The importance of antibody in the development of tolerance to the pyrogenic and toxic activities of gramnegative bacterial endotoxin has been an area of considerable controversy. Some investigators have concluded that anti-endotoxin antibodies represent the primary underlying mechanism (1); others have concluded that they play no demonstrable role $(2-6)$. It is well established that when small quantities of insoluble anti- 
gens are administered i.v., the spleen constitutes the major site of antibody formation, particularly during the initial week of immunization (7-9). Since these are the conditions under which endotoxin tolerance is generally studied, splenectomy was employed in the present investigations as a means of suppressing anti-endotoxin antibody production. The findings, which quantitate the resulting impairment of tolerance, demonstrate the contribution of anti-endotoxin antibody and establish the role of the spleen during the development of pyrogenic tolerance to endotoxin in the rabbit and man.

\section{METHODS}

Syringes, needles, and glassware were either of the sterile, pyrogen-free disposable type or were heated overnight in a dry-air oven at $180^{\circ} \mathrm{C}$ to eliminate extraneous pyrogens. A stock preparation of a Boivin-extracted Escherichia coliendotoxin (ET), ${ }^{1}$ serotype 0127B8 (Difco Laboratories, Detroit, Mich.) was employed throughout the study. This was diluted in sterile, pyrogen-free saline before use and stored at $4^{\circ} \mathrm{C}$. The aliquots for human testing were preheated at $100^{\circ} \mathrm{C}$ for $10 \mathrm{~min}$ and shown to be bacteriologically sterile.

Volunteers for these studies were fully informed 26-51yr-old male inmates of the Maryland House of Correction, Jessup, Md. Complete medical evaluations were performed to verify the fitness of each participant. The protocols for the studies were reviewed and approved by the University of Maryland Human Research Committee. In addition to man, healthy male New Zealand albino rabbits obtained from a uniform source and weighing approximately $2 \mathrm{~kg}$ were employed.

\section{Splenectomy}

Man. Splenectomized volunteers were healthy subjects whose spleens had been removed 7-11 yr previously after abdominal trauma. Endotoxin tolerance studies in these subjects were performed concomitantly with those in control subjects with intact spleens.

Rabbit. Animals were anesthetized with sterile, pyrogenfree pentobarbital (Diabutal, Diamond Labs, Des Moines, Iowa). The shaven abdominal wall was prepared with $2 \%$ tincture iodine and then washed with $70 \%$ alcohol and covered with sterile drapes, and the spleen was removed using sterile gloves and autoclaved instruments. Sham-operated animals were treated identically, except that the spleen was exposed through the incision and then replaced. The sterile silk sutures employed for closing the abdomen were removed after 7 days. Endotoxin tolerance studies were conducted concomitantly on the splenectomized and sham-operated animals after 3-4 wk of convalescence. After each study, the rabbits were sacrificed to verify completeness of splenectomy; the occasional animal with a small accessory spleen was excluded.

\section{Partial hepatectomy}

Anesthetization of rabbits and general sterile operative procedures were similar to those employed for splenectomy. The main liver mass, comprising approximately $75 \%$ of the total liver tissue, was extirpated after placing a sterile liga-

${ }^{1}$ Abbreviations used in this paper: ET, E. coli endotoxin; 6-MP, 6-mercaptopurine. ture around the portal area close to the inferior vena cava as described by McMaster and Drury (10). Free blood in the peritoneal cavity was removed by sterile sponging. The subsequent immediate mortality was $60 \%$. Sham-operated animals were treated identically, except that the main liver mass was not ligated but exposed through the incision and then replaced. Endotoxin tolerance studies were conducted concomitantly on the hepatectomized and sham-operated animals after 2-3 wk of convalescence. Since liver regeneration after partial hepatectomy was rapid, deficits in reticuloendothelial function were verified $24 \mathrm{~h}$ after completion of the endotoxin studies by assay of the blood clearance and hepatic and splenic uptake of i.v. colloidal ${ }^{198} \mathrm{Au}$. For each study, ${ }^{198} \mathrm{Au}$ tracer (Squibb E. R. and Sons, Inc., Princeton, N. J.) was added to nonradioactive colloidal gold, and assays were performed after i.v. injection of $2.5 \mathrm{mg} / \mathrm{kg}$ total colloid.

\section{Pyrogen assay}

Man. Studies were conducted in an air-conditioned room $\left(70^{\circ} \mathrm{F}\right)$ starting between 8 and 9 a.m. with the volunteers confined to bed and covered with a light blanket. Flexible thermocouples were inserted 6 inches into the rectum. Temperatures were monitored by a central telethermometer immediately before and every half $\mathrm{h}$ for $7 \mathrm{~h}$ after i.v. injection of the endotoxin. The resulting fever index was calculated from the area under the curve obtained by plotting the increment in temperature as a function of time on standard graph paper; a fever index of 100 reflected a $1^{\circ} \mathrm{F}$ rise in rectal temperature sustained for $1 \mathrm{~h}$. As a result of diurnal variations, temperatures seldom returned to preinjection values. In such instances, the fever curves were extrapolated to base line. In addition to the febrile responses, toxic subjective reactions after endotoxin administration were graded as follows: $0=$ asymptomatic; $1+=$ mild headache, anorexia $; 2+=$ moderate headache, anorexia, chills; $3+=$ severe headache, shaking chills, myalgia, nausea.

Rabbit. Animals were loosely restrained in stalls after acclimatization for $18-24 \mathrm{~h}$ in an air-conditioned room. Thermistor rectal probes were inserted 6 inches and connected to a central telethermometer. Temperatures were monitored 1-2 h before each experiment; animals exhibiting initial temperatures greater than $104^{\circ} \mathrm{F}$ or varying more than $0.5^{\circ} \mathrm{F}$ in any 30 -min control period were excluded. After endotoxin injection, temperatures were monitored every $30 \mathrm{~min}$ for $5 \mathrm{~h}$. Both the 3 -h temperature increment proposed by Watson and Kim (11) and the area under the fever curve (fever index) were calculated. The former paralleled the sensitivity of the latter as previously reported (12), was simpler to calculate, and yielded smaller standard deviations; the 3-h temperature increment was, therefore, selected as the parameter for assay of febrile responsiveness. As emphasized in previous studies, rectal temperature sometimes fell below the starting base line by the 4th or 5 th $\mathrm{h}$; downward extrapolation of the $3-\mathrm{h}$ increments to a line drawn between the initial and the 5-h sub-base-line temperature consistently reduced the standard deviations (13), and such extrapolation was routinely incorporated into the present assay system. Fig. 1 depicts the dose-response relationships in previously untested rabbits challenged with the standard ET preparation. It is evident that the sensitive portion of the dose-response relationship applies when the mean 3-h temperature increments fall between $1^{\circ}$ and $4^{\circ} \mathrm{F}$; the subsequent studies in rabbits were, therefore, conducted with dosages of endotoxin selected to evoke febrile responses within this sensitive range. 


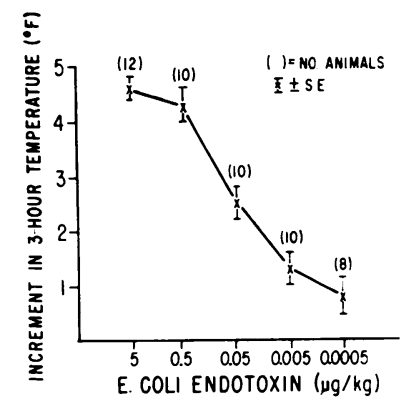

FIgURE 1 Relationship between ET dose and 3-h temperature increments in normal acclimatized rabbits.

\section{Antibody determinations}

Anti-endotoxin antibody titers, expressed as geometric means, were assayed by three methods: $(a)$ the bentonite flocculation technique as described by Wolff et al. (14): (b) the bactericidal technique as outlined by Weidanz and Landy (15); and (c) a modification of the Farr technique. The latter was performed as follow: duplicate sets $(1-\mathrm{ml}$ aliquots each) of twofold dilutions of serum in saline were placed in plastic test tubes, starting at 1:20. $100 \mu \mathrm{g}$ of unlabeled Boivin preparations of homologous ( $E$. coli 0127B8) or of heterologous (Salmonella typhimurium) endotoxin suspended in $1 \mathrm{ml}$ saline was added to each set of tubes, respectively. The homologous unlabeled endotoxin served to suppress both the nonspecific and the specific binding capacity of the serum; the heterologous unlabeled endotoxin served to suppress only the nonspecific binding capacity. The differences between the two sets of tubes, therefore, reflected the specific binding capacity. To determine this value, $10 \mathrm{~min}$ after addition of the unlabeled endotoxins, $1.0 \mu \mathrm{g}{ }^{51} \mathrm{Cr}$-labeled homologous ( $E$. coli $0127 \mathrm{~B} 8$ ) endotoxin in $0.1 \mathrm{ml}$ saline was added to all tubes with constant vortex stirring, and $10 \mathrm{~min}$ later the immune globulins (as well as all other proteins except for a trace of albumin as de-

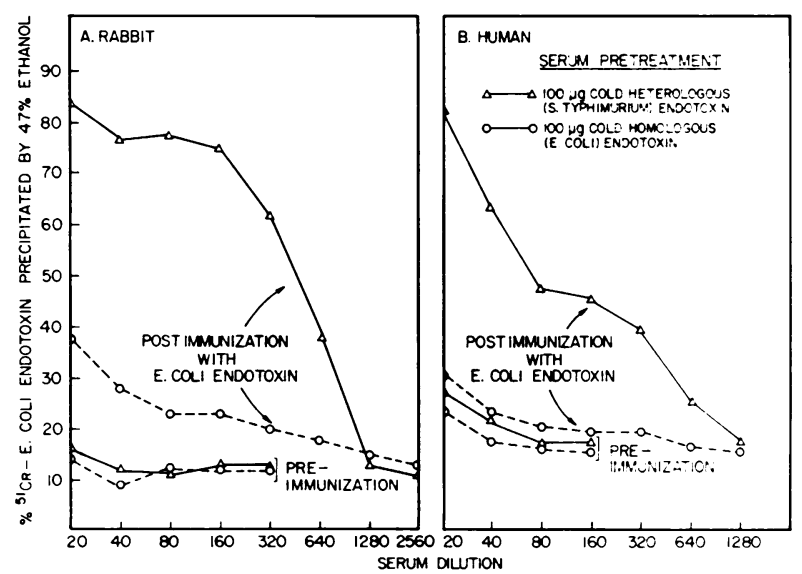

FIgUre 2 Typical anti-endotoxin antibody titrations utilizing the modified Farr technique. The endpoint for the postimmunization rabbit antiserum is $1: 1,280$ (panel A) and for the human antiserum 1:1,280 (panel B). Preimmunization titers in both species were consistently less than $1: 20$. tected electrophoretically) were precipitated by addition of $95 \%$ ethanol to yield a final concentration of $47 \%$. Unlike the $50 \%$ ammonium sulfate employed in the usual Farr method, this concentration of ethanol precipitated minimal $(10-15 \%){ }^{51} \mathrm{Cr}$-labeled endotoxin from saline suspensions. The quantity of precipitated labeled endotoxin in serum was measured by centrifugation for $10 \mathrm{~min}$ at $1,500 \mathrm{~g}$, removal of the upper half of the total volume (without disturbing the precipitate) and measuring radioactivity of the supranatant and corresponding infranatant in an automatic gamma well counter for sufficient time to permit reproducibility to within $5 \%$. Subtraction of the value of the supranatant from the infranatant gave the radioactivity of the precipitate. The antibody titer was taken as that dilution of antiserum capable of specifically binding the ${ }^{51} \mathrm{Cr}$-labeled endotoxin. Fig. 2 illustrates typical antibody titrations utilizing this modified Farr technique in the rabbit (panel A) and in man (panel B). Base-line preimmunization antibody titers were consistently less than $1: 20$.

\section{RESULTS}

\section{Rabbit}

Effect of splenectomy on the early and late phases of pyrogenic tolerance. To test the effect of splenectomy on late-phase pyrogenic tolerance, splenectomized and sham-operated rabbits were injected i.v. with sufficient ET to evoke fever within the sensitive dose-response range. Both groups responded comparably, Fig. 3A (day 0). Upon retesting 5 days later, both groups exhibited pyrogenic tolerance; splenectomized animals, however, exhibited significantly less tolerance $(P<0.01$, $t$ test). Indeed, the splenectomized animals developed more fever than did sham-operated controls given a

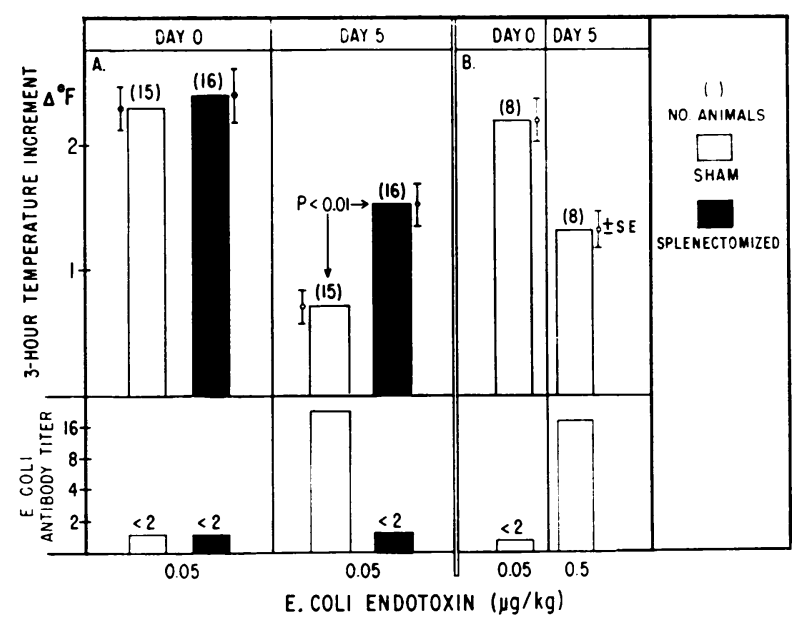

FIGURE 3 Effect of splenectomy on late phase pyrogenic tolerance. Panel A : note that splenectomy does not affect the initial pyrogenic responsiveness to endotoxin but does significantly impair anti-endotoxin antibody production and late phase tolerance 5 days after a single i.v. endotoxin injection in the rabbit. Panel B: a 10-fold increment in endotoxin dose $(0.5 \mu \mathrm{g} / \mathrm{kg})$ is required on day 5 to evoke febrile responses in animals with intact spleens comparable to the splenectomized group. 
10-fold greater challenge dose of the endotoxin on day 5, Fig. 3B. As shown in the lower half of Fig. 3, an unequivocal elevation in bentonite-flocculating anti-endotoxin antibody was evident on day 5 in the shamoperated animals, whereas no detectable elevations developed in the splenectomized group.

The subsequent studies were performed to test the effect of splenectomy on the response to repetitive daily endotoxin injections. As in the previous studies, i.v. injections of ET sufficient to evoke fever within the sensitive dose-response range induced initial mean febrile responses of equivalent magnitude in splenectomized and sham-operated animals, Fig. 4 (day 0 ). Upon retesting 24 h later (day 1) with a 10 -fold increment in endotoxin dosage, significant but equal tolerance was evident in both groups, the mean febrile responses being comparable to the day 0 reactions. Retesting with a further 10 -fold increment in endotoxin dose on day 2 evoked enhanced responses but again revealed no differences in pyrogenic reactivity of the splenectomized and sham-operated animals. No effect of splenectomy was therefore apparent during the early phase of endotoxin tolerance. In contrast, at $72 \mathrm{~h}$ (day 3 ), when circulating anti-endotoxin antibodies initially became detectable in sham-operated but not in splenectomized animals, highly significant impairment of pyrogenic tolerance became discernible in the splenectomized group $(P<0.001)$, Fig. 4. However, as the

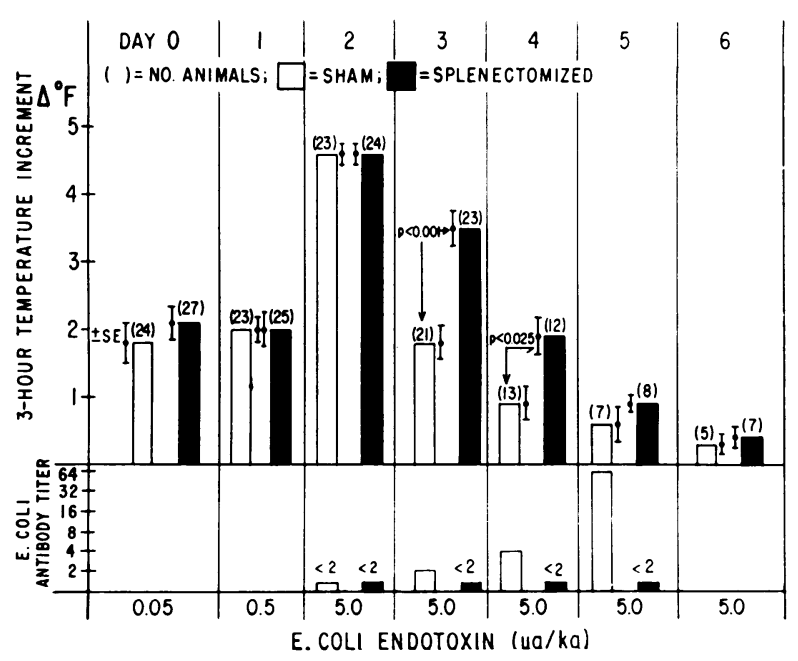

Figcre 4 Effect of splenectomy on early and late phase pyrogenic tolerance. Note that splenectomy does not affect the initial pyrogenic responsiveness to endotoxin or early phase (days 1 and 2) tolerance but suppresses anti-endotoxin antibody production and significantly retards the rate of subsequent tolerance development after repetitive daily i.v. endotoxin injections in the rabbit. (The decrement in animals after day 3 reflects random removal for obtaining plasma for passive transfer studies).

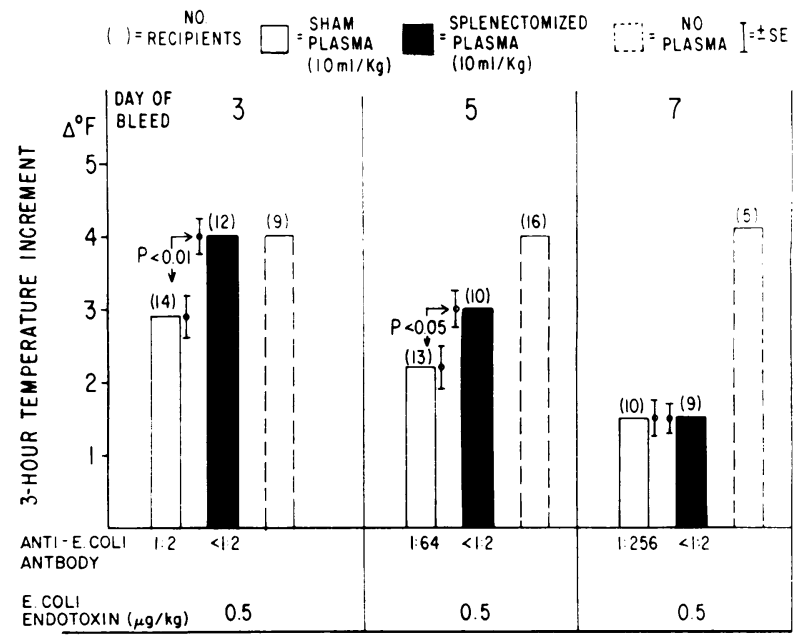

Figlre 5 Passive transfer of pyrogenic tolerance. $10 \mathrm{ml} / \mathrm{kg}$ pyrogen-free plasma aliquots from sham-operated or splenectomized donors (immunized with ET as outlined in Fig. 4) were administered i.v. $1 \mathrm{~h}$ before testing with the homologous endotoxin. Note the retarded production of transferable protective humoral factors in the splenectomized donors. The apparent lack of anti-endotoxin antibodies in the plasma from splenectomized donors on day 7 was shown to be relatable to the use of the bentonite flocculation technique; significant elevations in specific anti-endotoxin antibodies were found by the modified Farr method (see text).

daily i.v. endotoxin injections were continued, tolerance increased progressively and differences between the splenectomized and sham-operated groups decreased progressively despite the inability of splenectomized animals to develop circulating anti-endotoxin antibodies detectable by the bentonite flocculation technique, Fig. 4. Thus, splenectomy significantly retarded the rate of late-phase tolerance development after repetitive daily endotoxin administration but did not prevent its maturation.

Passize transfer of pyrogenic tolerance. To test the concept that the retarded late phase of pyrogenic tolerance in the splenectomized animal was attributable to depressed anti-endotoxin antibody synthesis rather than to loss of splenic reticuloendothelial cells required to clear and inactivate endotoxin, plasma transfer studies were performed. Pyrogen-free, pooled heparinized plasma $(10 \mathrm{ml} / \mathrm{kg})$ was infused i.v. into acclimatized healthy recipients $1 \mathrm{~h}$ before endotoxin challenge. Plasma from splenectomized donors obtained $24 \mathrm{~h}$ after the third endotoxin injection (given as outlined in Fig. 4) failed to transfer any detectable protection, whereas plasma from sham-operated controls transferred slight but definite protection $(P<0.01)$, Fig. 5. By day 5, each pool of plasma (from another group of donors) transferred definite tolerance, although that from the splenectomized donors remained less effective ( $P$ 
$<0.05$ ). By day 7 (using a third donor group) differences were no longer discernible in the level of transferable tolerance, even though plasma from splenectomized animals exhibited no detectable increments in bentonite-flocculating anti-endotoxin antibodies. Although seemingly lacking anti-endotoxin antibody, when the day 7 plasma from splenectomized donors was tested for specificity of passive protection, high levels of specificity were found, i.e., $10 \mathrm{ml} / \mathrm{kg}$ plasma transferred minimal pyrogenic tolerance to a heterologous (Salmonella typhimurium) endotoxin despite careful testing within the sensitive dose-response range. These latter findings conform with recently reported studies on the high level of specificity of passively transferred pyrogenic tolerance to endotoxin (25). As a result of these findings, the day 7 pooled rabbit plasma from the splenectomized animals was reexamined for anti-endotoxin antibodies by use of the modified Farr technique. An antibody titer of $1: 160$ was found, compared to the preimmunization titer of $\langle 1: 20$. The corresponding pooled plasma from the sham-operated animals exhibited a titer of 1:640 compared to the preimmunization titer of $\langle 1: 20$. Thus, the splenectomized rabbit is not totally immunosuppressed and is capable of producing appreciable circulating anti-endotoxin antibodies by day 7 in response to i.v. endotoxin; these antibodies, however, are primarily of a type incapable of flocculating bentonite particles coated with the specific antigen.

To confirm the observations that splenectomy does not ablate anti-endotoxin antibody responses but rather primarily removes the source of flocculating type antibodies, normal, splenectomized, and 6-mercaptopurinetreated rabbits were immunized i.v. with $3 \mu \mathrm{g}$ ET daily for 7 days and bled on day 8. Anti-endotoxin antibody titers were assayed by both the bentonite flocculation technique and by the modified Farr method (Table I). While antibody titers were equally suppressed in the splenectomized and 6-mercaptopurine-treated animals when measured by the bentonite flocculation method, the modified Farr method detected significantly greater rises in the splenectomized animals $(P<0.005)$. These findings militate against the possibility that the differences observed in antibody titers obtained by the bentonite flocculation and modified Farr techniques are attributable simply to differences in relative sensitivity of these two methods for the same antibody population. Additional evidence that splenectomy does not ablate anti-endotoxin antibody responses but rather selectively suppresses the production of antibodies with secondary activities was reflected in the ability of the modified Farr technique to detect rises in anti-ET antibody titers in splenectomized man despite no significant increments measurable by the extremely sensitive bactericidal method (see below).
TABLE I

Effect of Splenectomy and of 6-MP (18 mg/ky i.i'. daily) on Anti-Endotoxin Antibody Titers $24 h$ after seven Daily i.i. Injections of $3 \mu \mathrm{g}$ E. coli Endotoxin in the Rabbit*

\begin{tabular}{|c|c|c|}
\hline Group & $\begin{array}{l}\text { Bentonite } \\
\text { locculation } \\
\text { titer }\end{array}$ & $\begin{array}{l}\text { Modified } \\
\text { Farr titer }\end{array}$ \\
\hline \multicolumn{3}{|l|}{ Splenectomized } \\
\hline $\mathrm{S} 1$ & 4 & 320 \\
\hline $\mathrm{S} 2$ & 4 & 320 \\
\hline $\mathrm{S} 3$ & 4 & 160 \\
\hline $\mathrm{S} 4$ & 4 & 320 \\
\hline S5 & 4 & 320 \\
\hline Geometric mean: & 4 & 278 \\
\hline \multicolumn{3}{|l|}{ Controls } \\
\hline $\mathrm{C} 1$ & 512 & 1,280 \\
\hline $\mathrm{C} 2$ & 64 & 640 \\
\hline $\mathrm{C} 3$ & 512 & 1,280 \\
\hline $\mathrm{C} 4$ & 2,048 & 2,560 \\
\hline $\mathrm{C} 5$ & 256 & 1,280 \\
\hline Geometric mean: & 386 & 1,280 \\
\hline \multicolumn{3}{|l|}{ 6-MP‡ } \\
\hline M1 & 8 & 320 \\
\hline M2 & 16 & 160 \\
\hline M3 & 8 & 20 \\
\hline M4 & 8 & 40 \\
\hline M5 & 16 & 80 \\
\hline M6 & 2 & 80 \\
\hline M7 & 4 & 80 \\
\hline M8 & 2 & 20 \\
\hline Geometric mean: & 6 & 67 \\
\hline \multicolumn{3}{|l|}{ Controls $\ddagger$} \\
\hline $\mathrm{C} 1$ & 512 & 1,280 \\
\hline $\mathrm{C} 2$ & 256 & 640 \\
\hline $\mathrm{C} 3$ & 256 & 640 \\
\hline $\mathrm{C} 4$ & 256 & 320 \\
\hline $\mathrm{C} 5$ & 128 & 320 \\
\hline \multirow[b]{2}{*}{ Geometric mean: } & 256 & 640 \\
\hline & 256 & 562 \\
\hline
\end{tabular}

* Preimmunization base-line titers were less than 2 by the bentonite flocculation technique and less than 20 by the modified Farr method.

‡ Sera kindly provided by Dr. Sheldon M. Wolff, National Institute of Allergy and Infectious Diseases, National Institutes of Health.

Effect of partial hepatectomy on pyrogenic tolerance. To further test the concept that the retardation of the late phase of pyrogenic tolerance in the splenectomized rabbit was mediated by the reduced anti-endotoxin anti- 
body synthesis and not by a loss of a portion of the reticuloendothelial system required to clear and inactivate the endotoxin, tolerance acquisition was quantitated 2-3 wk after partial hepatectomy. The partially hepatectomized animals, in contrast to the splenectomized group, exhibited no suppression of anti-endotoxin antibody synthesis and acquired pyrogenic tolerance at rates entirely comparable to sham-operated controls, Fig. 6. That reticuloendothelial phagocytic function was impaired in these partially hepatectomized rabbits was confirmed by measuring uptake of radioactive colloidal gold after administration i.v. Although approximately $75 \%$ of the total liver was initially ablated, restoration of phagocytically active reticuloendothelium occurred such that the hepatic depletion was now evident only by slight retardation in blood clearance of the colloidal ${ }^{188} \mathrm{Au}$ and by only a $5 \%$ decrease in the hepatic contribution to the total uptake of injected colloid, Fig. 7. This latter difference, however, was significant $(P<$ 0.005 at $3 \mathrm{~h}$ and $P<0.02$ at $24 \mathrm{~h})$. Since the splenic contribution to total uptake of injected colloid at $24 \mathrm{~h}$ amounted to only $1 \%$, it is apparent that despite regeneration, the partial hepatectomy accomplished the removal of more functional reticuloendothelial tissue than did splenectomy. Moreover, since these data were obtained after completion of the endotoxin tolerance studies, even greater deficits of functional hepatic reticuloendothelium presumably existed during the actual period of endotoxin testing.

\section{Man}

The development of pyrogenic tolerance and of antiendotoxin antibodies after i.v. E. coli endotoxin was compared in healthy volunteers with and without spleens. Since marked initial subjective toxic responses

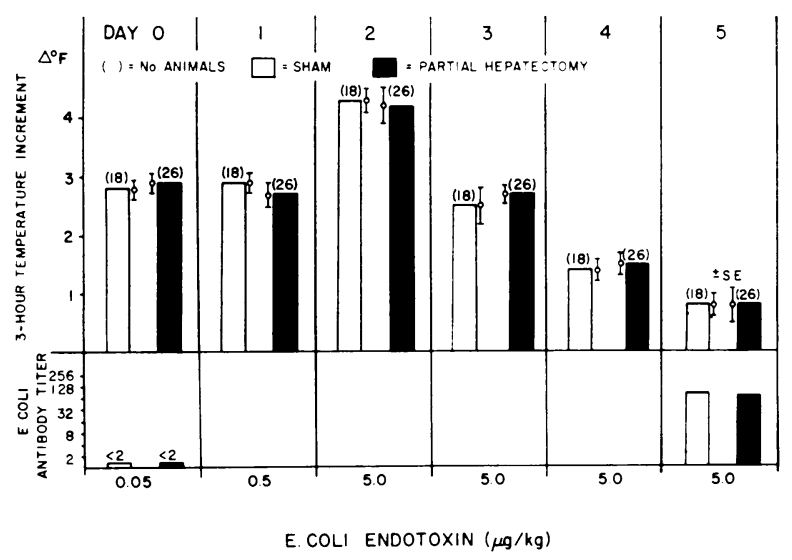

Figure 6 Effect of partial hepatectomy on pyrogenic tolerance. Note that partial hepatectomy does not suppress anti-endotoxin antibody production or retard late-phase pyrogenic tolerance in the rabbit.

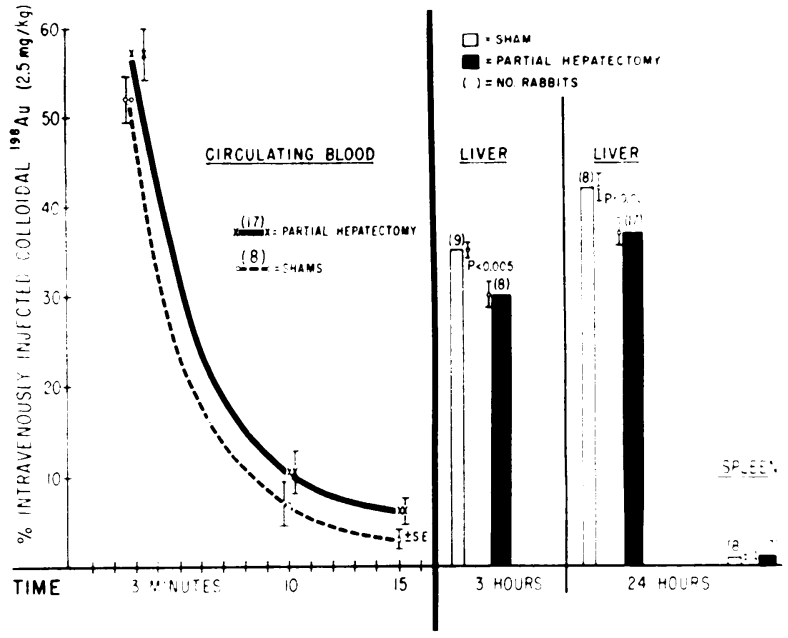

FIGLRE 7 Confirmation of impaired hepatic reticuloendothelial phagocytic activity in the partially hepatectomized rabbits depicted in Fig. 6. Note that the reduction in the hepatic contribution to uptake of colloidal gold after partial hepatectomy exceeds the entire splenic contribution.

developed in all volunteers given the standard test dose of ET $(0.01 \mu \mathrm{g} / \mathrm{kg})$, and since augmented toxic responses rather than tolerance may occur in man when endotoxin is re-administered $24 \mathrm{~h}$ later $(5,16-19)$, retesting was delayed for 5 days, i.e., only the late phase of tolerance was studied. The results are outlined in Fig. 8 and can be summarized as follows:

(a) The spleen plays no important role in the initial response of man to submicrogram quantities of i.v. endotoxin. The initial (day 0) pyrogenic and subjective toxic responses of splenectomized volunteers were comparable to those of the controls (group A).

(b) The human spleen plays an important role in the production of anti-endotoxin antibodies to i.v. endotoxin, at least during the initial 10 days. Control volunteers given $0.01 \mu \mathrm{g} / \mathrm{kg}$ of the ET (group A) developed marked rises in bentonite flocculating and bactericidal antibody titers, whereas no detectable titers developed in the splenectomized group. The consistency of this pattern is especially striking when the antibody responses for individuals within each group are analyzed, Table II. In contrast to flocculating and bactericidal antibody, unequivocal although blunted increases in anti-endotoxin antibodies could be detected in the splenectomized volunteers by use of the modified Farr technique.

(c) The spleen plays an important role in the development of the late phase of tolerance after a single i.v. injection of endotoxin in man. Tolerance to ET developed 5 days after the initial injection in both control (group A) and splenectomized volunteers, but its development was unequivocally impaired in the splenectomized group. Thus, compared to their respective initial 
TABLE II

Effect of Splenectomy on Bentonite Flocculating and Bactericidal Antibodies to i.v. E. coli Endotoxin $(0.01 \mu \mathrm{g} / \mathrm{kg}$ i.v. $)$ in Healthy Human Volunteers

\begin{tabular}{|c|c|c|c|c|c|c|c|c|}
\hline Subject & Day....0* & 1 & 2 & 3 & 4 & $5 *$ & $7 *$ & $1 \mathrm{C}^{*}$ \\
\hline \multicolumn{9}{|c|}{ Splenectomized } \\
\hline B. C. & $\begin{array}{l}<2 \ddagger \\
(900) \S\end{array}$ & $\begin{array}{c}<2 \\
(1,600)\end{array}$ & $\begin{array}{c}<2 \\
(1,420)\end{array}$ & $<2$ & $\begin{array}{l}<2 \\
(800)\end{array}$ & $<2$ & $\begin{array}{l}<2 \\
(50)\end{array}$ & $<2$ \\
\hline J. O. & $\begin{array}{l}<2 \\
(95)\end{array}$ & $\begin{array}{l}<2 \\
(58)\end{array}$ & $\begin{array}{l}<2 \\
(100)\end{array}$ & $<2$ & $\begin{array}{l}<2 \\
(95)\end{array}$ & $<2$ & $\begin{array}{l}<2 \\
(<32)\end{array}$ & $<2$ \\
\hline J. P. & $\begin{array}{l}<2 \\
(98)\end{array}$ & $\begin{array}{l}<2 \\
(58)\end{array}$ & $\begin{array}{l}<2 \\
(88)\end{array}$ & $\begin{array}{l}<2 \\
(74)\end{array}$ & $\begin{array}{l}<2 \\
(70)\end{array}$ & $\begin{array}{l}<2 \\
(76)\end{array}$ & $\begin{array}{l}<2 \\
\quad(210)\end{array}$ & $<2$ \\
\hline \multicolumn{9}{|c|}{ Controls } \\
\hline L. G. & $\begin{array}{l}<2 \\
(32)\end{array}$ & $<2$ & $<2$ & $<2$ & $<2$ & 32 & $\begin{array}{l}64 \\
(900)\end{array}$ & 128 \\
\hline A. M. & $\begin{array}{c}<2 \\
(2,800)\end{array}$ & $\begin{array}{c}<2 \\
(3,000)\end{array}$ & $\begin{array}{c}<2 \\
(4,000)\end{array}$ & $<2$ & $\begin{array}{c}<2 \\
(4,700)\end{array}$ & 64 & $\begin{array}{l}512 \\
(11,000)\end{array}$ & 512 \\
\hline R. B. & $\begin{array}{l}<2 \\
(35)\end{array}$ & $<2$ & $<2$ & $<2$ & $<2$ & 128 & $\begin{array}{l}256 \\
(35,000)\end{array}$ & 512 \\
\hline E. W. & $\begin{array}{l}<2 \\
(200)\end{array}$ & $<2$ & $<2$ & $<2$ & $<2$ & 128 & $\begin{array}{c}256 \\
(>100,000)\end{array}$ & 512 \\
\hline N. H. & $\begin{array}{l}<2 \\
(275)\end{array}$ & $\begin{array}{l}<2 \\
(240)\end{array}$ & $\begin{array}{l}<2 \\
(255)\end{array}$ & $\begin{array}{c}<2 \\
(135)\end{array}$ & $\begin{array}{l}<2 \\
(940)\end{array}$ & $\begin{array}{c}64 \\
(1,120)\end{array}$ & $\begin{array}{l}128 \\
(5,200)\end{array}$ & $\begin{array}{l}512 \\
(12,000)\end{array}$ \\
\hline D. D. & $\begin{array}{l}<2 \\
(350)\end{array}$ & $\begin{array}{l}<2 \\
(420)\end{array}$ & $\begin{array}{l}<2 \\
(440)\end{array}$ & $\begin{array}{c}<2 \\
(610)\end{array}$ & $\begin{array}{c}<2 \\
(1,300)\end{array}$ & $\begin{array}{c}64 \\
(12,000)\end{array}$ & $\begin{array}{l}128 \\
(96,000)\end{array}$ & $\begin{array}{c}256 \\
(>100,000)\end{array}$ \\
\hline
\end{tabular}

* Serum for antibody obtained immediately before endotoxin injections. The endotoxin was given on days $0,5,7$, and 10 .

$\ddagger$ Reciprocal of titer determined by bentonite flocculation technique.

$\S$ Reciprocal of titer determined by bactericidal technique.

responses, the fever indices decreased by $35,42,45$, 47,58 and $68 \%$ in the control subjects whereas in the splenectomized group the decline was only 7,23 , and $31 \%(P<0.02)$. When additional i.v. endotoxin injections were administered after the 5 th day, tolerance increased in all volunteers, but its maturation was significantly retarded in the splenectomized group. Thus, compared to their respective initial responses, the fever indices decreased by $47,56,61,71,73$, and $73 \%$ on day 7 and by $66,66,68,75,77$, and $99 \%$ on day 10 in the control subjects whereas in the splenectomized group the decline was only 24,38 , and $48 \%$ on day 7 and 44, 47, and $69 \%$ on day $10(P<0.02$ for day 7 and $P<0.05$ for day 10). Fig. 8 depicts the mean rates of tolerance retardation (splenectomized vs. control group A).

(d) Quantitative studies further emphasize the importance of the human spleen for anti-endotoxin antibody formation and late-phase tolerance. The impairment of both these latter parameters seen in the splenectomized volunteers on day 7 could be reproduced in volunteers with intact spleens only by reducing the immunizing doses of ET to levels extrapolated to fall between $1 / 10$ and $1 / 100$ of those used in the splenectomized group (groups B and C, respectively). (e) Late-phase tolerance in man bears no direct relationship to the initial pyrogenic or toxic responses to endotoxin. In volunteers with intact spleens, pyrogenic tolerance on day 7 was comparable regardless of whether immunization was carried out with $0.01 \mu \mathrm{g} / \mathrm{kg}$ (group A) or with $0.001 \mu \mathrm{g} / \mathrm{kg}$ (group B) ET. The former dose evoked severe pyrogenic and subjective toxic responses, while the latter evoked no detectable toxic reactions. The common denominator underlying these differing immunizing doses of endotoxin was their elicitation of substantial increments in anti-endotoxin antibodies at the time of tolerance testing. Only when the immunizing dose of the ET was reduced to 0.0001 $\mu \mathrm{g} / \mathrm{kg}$ (group C), a quantity that elicited minimal increments in anti-endotoxin antibody, was day 7 tolerance significantly impaired.

\section{DISCUSSION}

It is now recognized that several mechanisms underlie the development of tolerance to the pyrogenic activity of gram-negative bacterial endotoxins. One of these mechanisms appears to be related to a direct effect of endotoxin upon the target cells that synthesize and release endogenous pyrogens. This mechanism, which has been termed the "refractory state" develops within hours, 


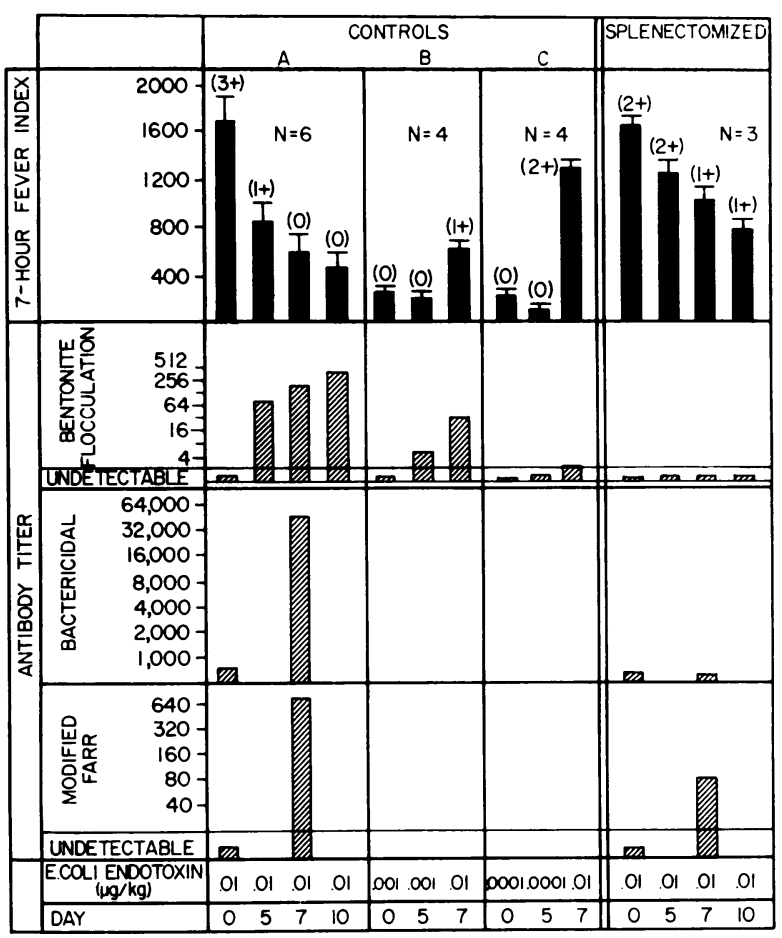

Figure 8 Effect of splenectomy on endotoxin tolerance in man. Comparison of responses of control subjects (group A) with the splenectomized group demonstrates that splenectomy dces not affect the initial responsiveness of man to i.v. endotoxin but markedly impairs anti-endotoxin antibody production and significantly retards late phase pyrogenic tolerance acquisition. Responses of additional control volunteers immunized with $1 / 10$ and $1 / 100$ of the endotoxin dosages (groups B and C, respectively) permit quantitation of the high degree of anti-endotoxin antibody suppression and tolerance retardation in the splenectomized volunteers. (Numbers in parentheses above black bars represent subjective toxic responses; see text for grading. Brackets above black bars indicate $1 \mathrm{SE}$ of the mean).

is specific for endotoxins as a class although lacking " 0 " specificity, is not transferable with serum, and wanes within several days after one i.v. endotoxin injection $(13,19-23)$. A second mechanism appears to be related to the activity of anti-endotoxin antibodies. This mechanism, which can be termed "immunity," develops only after several days (or more rapidly during an anamnestic response), is transferable with serum, possesses appreciable " 0 " specificity, and is relatively persistent $(13,23-25)$. When a single bolus of endotoxin is administered i.v. and pyrogenic tolerance is assessed at serial intervals thereafter, the refractory and immune mechanisms become apparent as temporally distinct early and late phases of tolerance $(13,23)$. When endotoxin is administered repetitively at daily (or more closely spaced) intervals, pyrogenic tolerance increases as the refractory and immune states appear to become superimposed (26). When the daily injections of endotoxin are discontinued, pyrogenic tolerance decreases markedly during the subsequent several days but then persists at a significant residual level for at least several months in association with elevated specific anti-endotoxin antibody titers. These latter observations, documented by Mulholland et al. (21), have been postulated to reflect the rapid waning of the refractory state, exposing the more persistent underlying immune state (26). The present studies, utilizing the splenectomized host, were designed to test certain facets of the above hypothesis.

Although the splenic contribution to the total reticuloendothelial system (RES) clearance of circulating endotoxin is minor-less than $3 \%$ of i.v. endotoxin is fixed within the spleen (27) - the spleen plays a major role in the production of anti-endotoxin antibodies (28). If the concepts outlined above are valid, then splenectomy should not impair the development of the early (refractory) phase of pyrogenic tolerance but should significantly impair the later (immune) phase. Moreover, it would be predicted that the degree of impairment of tolerance would be dependent upon the schedule of endotoxin administration. Thus, if the late phase of pyrogenic tolerance after a single i.v. injection of endotoxin is indeed based primarily upon anti-endotoxin antibodies, it should be significantly diminished in the splenectonized host. In contrast, during repetitive daily i.v. injections of endotoxin not only do nonantibody tolerance mechanisms appear to be operative (e.g. the refractory state), but, in addition, during such hyperimmunization increasing amounts of anti-endotoxin antibodies would be derived from extrasplenic sites. Landy et al. have demonstrated that although the spleen is the principal organ involved in antibody responses to i.r. endotoxin, other lymphoid tissues participate, including bone marrow, peripheral blood leukocytes, and thymus (28). The present studies confirm the participation of extrasplenic sites in anti-endotoxin antibody production and indicate that in both rabbit and man such extrasplenic antibody possesses minimal secondary (flocculating and bactericidal) activities. Since such anti-endotoxin antibodies are nevertheless capable of transferring pyrogenic tolerance $(25,29)$ and since alternative protective mechanisms appear to be activated during closely spaced endotoxin injections, splenectony would be expected only to retard, rather than prevent the development of pyrogenic tolerance during repetivitive daily i.v. administration of endotoxin. The present studies, employing doses of endotoxin carefully selected to evoke febrile responses within the sensitive dose-response range, support these concepts. Thus, whereas splenectomy failed to affect the initial pyrogenic responses or the development of pyrogenic tolerance during the subsequent $48 \mathrm{~h}$ after i.v. ET administra- 
tion, unequivocal impairment of the later phase of pyrogenic tolerance was observed in both splenectomized rabbits and man. This was evidenced by significantly reduced levels of tolerance 5 days after a single i.v. injection of endotoxin and by significantly retarded rates of tolerance development commencing $72 \mathrm{~h}$ after repetitive daily i.v. administration of endotoxin. The defect in the late phase of tolerance in man was such that to produce equivalent impairment in volunteers with intact spleens the immunizing doses of endotoxin had to be reduced to levels extrapolated to fall between $1 / 10$ and $1 / 100$ of those used in the splenectomized volunteers. The impairment of late-phase tolerance developed concomitantly with the impaired capacity to produce circulating antiendotoxin antibodies. In addition to this temporal relationship, several other observations indicated that such suppression of antibody production was causally related to the impairment of late phase tolerance. Thus, $(a)$ the appearance of humoral factors capable of passively transferring high levels of specific pyrogenic tolerance was significantly retarded after splenectomy in the rabbit; $(b)$ to produce impairment of the late phase of pyrogenic tolerance in human volunteers with intact spleens the immunizing doses of endotoxin had to be reduced to levels that virtually eliminated production of circulating anti-endotoxin antibodies; and $(c)$ the late phase of pyrogenic tolerance was not impaired in partially hepatectomized rabbits lacking significantly more functional RES than splenectomized animals but capable of normal anti-endotoxin antibody production. The findings, considered collectively, indicate that the impairment of the late phase of pyrogenic tolerance after splenectomy is based primarily upon suppression of anti-endotoxin antibody production rather than upon loss of splenic reticuloendothelium required to clear and inactivate endotoxin.

In earlier studies in which antibody synthesis was suppressed in rabbits by 6-mercaptopurine (6-MP), no impairment of pyrogenic tolerance to endotoxin was observed (6). This probably can be attributed to the fact that with the dosages employed $(18 \mathrm{mg} / \mathrm{kg}) 6-\mathrm{MP}$ does not eliminate anti-endotoxin antibody synthesis and that the tolerant responses were not quantitated until $24 \mathrm{~h}$ after seven successive daily i.v. endotoxin injections. The small but nevertheless unequivocal increments in circulating anti-endotoxin antibodies in the 6-MP-treated animals, together with the additional tolerance mechanisms activated by the repetitive daily endotoxin injections, could preclude detection of tolerance impairment late in the course of such toxin administration. Studies in our laboratory in rabbits given seven successive daily i.v. injections of 6-MP and ET confirm those of Wolff and co-workers (6) in that a high level of pyrogenic tolerance developed by day 8 , comparable to that in non-6-MP-treated controls. When each of the preceding daily responses was examined, however, it was observed that the 6-MP-treated animals exhibited unaltered early phase pyrogenic tolerance but significant retardation of the late phase, commencing at $72 \mathrm{~h}$, coincident with the onset of impaired circulating anti-endotoxin antibody production and identical with that seen in the splenectomized rabbits. Moreover, utilizing quantitative plasma transfer studies, this delay in tolerance maturation was found to parallel the delayed production of humoral factors capable of transferring high levels of specific tolerance. Pyrogenic tolerance to endotoxin has also been reported to be unimpaired in patients with "agammaglobulinemia" $(4,5)$. However, in those patients studied for tolerance only the absence of antibody responses to the $\mathrm{H}$ antigen of the typhoid vaccine was recorded; the absence of anti-endotoxin antibody responses was not documented, nor were direct binding-assay techniques, the importance of which is evidenced from the present data, utilized to exclude such antibody responses. Moreover, since the endotoxin was administered repetitively at daily intervals, suppression of anti-endotoxin antibody-synthesizing capability would be expected primarily to retard rather than prevent the development of late pyrogenic tolerance. In this regard, it is of interest that in the one illustration that depicts in detail the daily febrile responses of a patient with "agammaglobulinemia" and of a normal control subject, impressive retardation of pyrogenic tolerance is demonstrated in the former (5). Thus, the earlier data do not exclude a significant contribution of anti-endotoxin antibodies to the late phase of pyrogenic tolerance. Rather, recent reports from a number of laboratories all provide additional evidence supporting the concept of a significant contribution of such antibodies, especially those possessing " 0 " specificity, to this phase of endotoxin tolerance $(13,23-25,30-35,35 a)$.

Based upon the above considerations the spleen in both rabbit and man can be regarded as an organ that is not important for protection against the initial pyrogenic and subjective toxic responses to microgram quantities of i.v. endotoxin, or essential for tolerance acquisition to this toxin but that by virtue of its anti-endotoxin antibody-forming potential contributes significantly to the late phase of pyrogenic tolerance after a single i.v. endotoxin injection and enhances significantly the rate of its development after repetitive daily i.v. administration of the toxin. These conclusions are consistent with and extend the findings from other laboratories indicating that the spleen is not important for protection of the guinea pig (36) or mouse (37) against the lethal activity of endotoxin, or for tolerance to this activity when assessed $24 \mathrm{~h}$ after five-daily sublethal injections (37). It is stressed that the present conclusions are re- 
stricted to pyrogenic tolerance that develops to an endotoxin derived from a smooth (wild type) gram-negative bacterial strain. The contribution of the spleen to late-phase tolerance against endotoxins from rough gram-negative bacterial mutant strains or the purified lipid $\mathrm{A}$, wherein antibodies to common core and to lipid A rather than to " 0 " specific antigens appear to be primarily involved $(25,31,38,39)$, remains to be defined.

\section{ACKNOWLEDGMENTS}

The authors express their appreciation to the volunteers who contributed to these studies and to the officials of the Maryland House of Correction, Jessup, Md., for their generous cooperation and interest without which these studies could not have been accomplished. Appreciation is also expressed to Dr. Bernard DuBuy for his assistance with the development of the modified Farr technique for anti-endotoxin antibody assays.

This investigation was supported by grant AI 07052 from the National Institutes of Health and by the U. S. Army Medical Research and Development Command, contract DA-49-193-MD-2867.

\section{REFERENCES}

1. Kim, Y. B., and D. W. Watson. 1965. Modification of host responses to bacterial endotoxins. II. Passive transfer of immunity to bacterial endotoxin with fractions containing $19 \mathrm{~S}$ antibodies. J. Exp. Med. 121: 751-759.

2. Beeson, P. B. 1947. Tolerance to bacterial pyrogens. II. Role of the reticulo-endothelial system. J. Exp. Med. 86: $39-44$.

3. Morgan, H. R. 1948. Tolerance to the toxic action of somatic antigens of enteric bacteria. J. Immunol. 59: 129-134.

4. Good, R. A., and R. L. Varco. 1955. A clinical and experimental study of agammaglobulinemia. J-Lancet. 75: 245-271.

5. Good, R. A., and S. J. Zac. 1956. Disturbances in gamma globulin synthesis as "experiments of nature". Pediatrics. 18 : 109-149.

6. Wolff, S. M., J. H. Mulholland, S. B. Ward, M. Rubenstein, and P. D. Mott. 1965. Effect of 6-mercaptopurine on endotoxin tolerance. J. Clin. Invest. 44: 1402-1409.

7. Rowley, D. A. 1950. The effect of splenectomy on the formation of circulating antibody in the adult male albino rat. J. Immunol. 64: 289-295.

8. Rowley, D. A. 1950. The formation of circulating antibody in the splenectomized human being following intravenous injection of heterologous erythrocytes. $J$. Immunol. 65 : 515-521.

9. Draper, L. R., and D. H. Süssdorf. 1957. The serum hemolysin response in intact and splenectomized rabbits following immunization by various routes. J. Infect. Dis. 100: 147-161.

10. McMaster, P. D., and D. R. Drury. 1929. The production of partial liver insufficiency in rabbits. J. Exp. Med. $49:$ 745-758.

11. Watson, D. W., and Y. B. Kim. 1963. Modification of host responses to bacterial endotoxins I. Specificity of pyrogenic tolerance and the role of hypersensitivity in pyrogenicity, lethality, and skin reactivity. J. Exp. Med. 118: 425-446.
12. Wolff, S. M., Mulholland, J. H., and S. B. Ward. 1965. Quantitative aspects of the pyrogenic response of rabbits to endotoxin. J. Lab. Clin. Med. 65: 268-276.

13. Greisman, S. E., Young, E. J., and F. A. Carozza, Jr. 1969. Mechanisms of endotoxin tolerance V. Specificity of the early and late phases of pyrogenic tolerance. $J$. Immunol. 103 : 1223-1236.

14. Wolff, S. M., Ward, S. B., and M. Landy. 1963. Serologic properties of bentonite particles coated with microbial polysaccharides. Proc. Soc. Exp. Biol. Med. 114: 530-536.

15. Weidanz, W. P., and M. Landy. 1963. A simplified method for bactericidal assay of natural antibodies against gram-negative bacteria. Proc. Soc. Exp. Biol. Med. 113: 861-867.

16. Kunde, M. M., Hall, G. W., and F. J. Gerty. 1926. Nonspecific protein therapy in general paralysis. J. Am. Med. Assoc. 87: 1376-1377.

17. Page, A. R., and R. A. Good. 1957. Studies on cyclic neutropenia. Am. J. Dis. Child. 94: 623-661.

18. Greisman, S. E., Wagner, H. N., Jr., Iio, M., and R. B. Hornick. 1964. Mechanisms of endotoxin tolerance. II. Relationship between endotoxin tolerance and reticuloendothelial system phagocytic activity in man. J. Exp. Med. 119: 241-264 + plates 16, 17.

19. Greisman, S. E., and W. E. Woodward. 1965. Mechanisms of endotoxin tolerance. III. The refractory state during continuous intravenous infusions of endotoxin. J. Exp. Med. 121: 911-933.

20. Braude, A. I., Zalesky, M., and H. Douglas. 1958. The mechanism of tolerance to fever. J. Clin. Invest. 37: 880-881. (Abstr.)

21. Mulholland, J. H., S. M. Wolff, A. L. Jackson, and M. Landy. 1965. Quantitative studies of febrile tolerance and levels of specific antibody evoked by bacterial endotoxin. J. Clin. Invest. 44 : 920-928.

22. Greisman, S. E., Young, E. J., and W. E. Woodward. 1966. Mechanisms of endotoxin tolerance. IV. Specificity of the pyrogenic refractory state during continuous intravenous infusions of endotoxin. J. Exp. Med. 124: $983-1000$.

23. Milner, K. C. 1973. Patterns of tolerance to endotoxin. J. Infect. Dis. 128 (Suppl.).: S237-S245.

24. Greisman, S. E., and E. J. Young. 1969. Mechanisms of endotoxin tolerance. VI. Transfer of the "anamnestic" tolerant response with primed spleen cells. J. Immunol. 103: 1237-1241.

25. Greisman, S. E., Young, E. J., and B. DuBuy. 1973. Mechanisms of endotoxin tolerance. VIII. Specificity of serum transfer. J. Immunol. 111: 1349-1360.

26. Greisman, S. E., and R. B. Hornick. 1973. Mechanisms of endotoxin tolerance with special reference to man. J. Infect. Dis. 128(Suppl.): S265-S276.

27. Carey, F. J., Braude, A. I., and M. Zalesky. 1958. Studies with radioactive endotoxin. III. The effect of tolerance on the distribution of radioactivity after intravenous injection of Escherichia coli endotoxin labeled with $\mathrm{Cr}^{51}$. J. Clin. Invest. 37: 441-457.

28. Landy, M., Sanderson, R. P., and A. L. Jackson. 1965. Humoral and cellular aspects of the immune response to the somatic antigen of Salmonella enteriditis. J. Exp. Med. 122 : 483-504.

29. Braude, A. I., Jones, J. L., and H. Douglas. 1963. The behavior of Escherichia coli endotoxin (somatic antigen) during infectious arthritis. J. Immunol. 90: 297311 . 
30. Radvany, R., Neale, N. L., and A. Nowotny. 1966. Relation of structure to function in bacterial O-antigens. VI. Neutralization of endotoxic O-antigens by homologous O-antibody. Ann. N. Y. Acad. Sci. 133: 763-786.

31. Braude, A. I., and H. Douglas. 1972. Passive immunization against the local Shwartzman reaction. J. Immunol. 108: 505-512.

32. Müller-Ruchholtz, M., and H. Sprockhoff. 1969. Spezifität der Toleranz bakterieller Pyrogene bei Kaninchen. Z. Immunitaetsforsch. Allerg. Klin. Immunol. 138: 5061.

33. Ralovich, B., and C. Láng. 1971. Antipyrogenic effect of immune sera. Z. Immunaetsforsch. Exp. Klin. Immunol. 141 : 251-257.

34. Ralovich, B., and C. Láng. 1972. Antipyrogenic effect in actively immunized rabbits. Acta Physiol. Acad. Sci. Hung. 42: 75-78.

35. Ziegler, E. J., Douglas, H., and A. I. Braude. 1973. Human antiserum for prevention of the local Shwartz- man reaction and death from bacterial lipopolysaccharides. J. Clin. Invest. 52: 3236-3238.

35a. Ralovich, B., L. Emody, and C. Lang. 1974. Problems of antiendotoxic immunity. J. Hyg. Epidemiol. Microbiol. Immunol. (Prague). 18: 439-446.

36. Farrar, W. E., Jr. 1965. Endotoxin detoxification by guinea pig tissue homogenates and possible significance of this reaction in vivo. Proc. Soc. Exp. Biol. Med. 118: 218-221.

37. Agarwal, M. K., Parant, M., and F. Parant. 1972. Role of spleen in endotoxin poisoning and reticuloendothelial function. Br. J. Exp. Pathol. 53: 485-491.

38. Rietschel, E. T., Kim, Y. B., Watson, D. W., Galanos, C., Lüderitz, O., and O. Westphal. 1973. Pyrogenicity and immunogenicity of lipid A complexed with bovine serum albumin or human serum albumin. Infect. Immun. 8: 173-177.

39. Rietschel, E. T. 1975. Chemical structure and biological activity of endotoxins (lipopolysaccharides) and lipid A. Naunj'n-Schmiedebergs Arch. Pharmakol. 287: 73-84. 